\title{
Complications Leading to Sudden Cardiac Death in Pulmonary Arterial Hypertension
}

\author{
Eftychia A Demerouti MD PhD, Athanassios N Manginas MD PhD, \\ George D Athanassopoulos MD PhD, and George T Karatasakis MD PhD
}

\author{
Introduction \\ Plausible Causes of Arrhythmia \\ Non-arrhythmic Causes \\ Left Main Compression Syndrome \\ Pulmonary Artery Dissection and Rupture \\ Hemoptysis \\ Syncope in PAH \\ Cardiac Arrest and Resuscitation in PAH Patients \\ Summary
}

\begin{abstract}
Pulmonary arterial hypertension (PAH) is a disease of small pulmonary arteries, characterized by vascular proliferation and remodeling. Progressive increase in pulmonary vascular resistance ultimately leads to right ventricular heart failure and death. PAH-specific drug therapy has improved clinical outcomes and survival. While the survival is better, progression of pulmonary vasculopathy contributes to pulmonary artery dilatation. Left main compression syndrome, pulmonary artery dissection, pulmonary artery rupture, and severe hemoptysis are reported as complications leading to sudden cardiac death, an event encountered more often in PAH patients. The advent of PAHtargeted drug therapy has reduced referral for lung transplantation; however, severe complications require rapid diagnosis, decision making, and possible registration on a lung transplantation waiting list. PAH referral centers provide multidisciplinary emergency care and specific therapeutic management, contributing to improved quality of life and survival for PAH patients. We review the complications leading to sudden death in PAH. Key words: pulmonary hypertension; pulmonary artery dissection; pulmonary artery rupture; left main compression syndrome. [Respir Care 2013;58(7):12461254. () 2013 Daedalus Enterprises]
\end{abstract}

\section{Introduction}

Pulmonary arterial hypertension (PAH) is a devastating disease, leading to right ventricular (RV) heart failure and

The authors are affiliated with the Cardiology Department, Onassis Cardiac Surgery Center, Athens, Greece; with the exception of Dr Manginas, who is affiliated with Cardiology and Interventional Cardiology Department, Mediterraneo Hospital, Athens, Greece

The authors have disclosed no conflicts of interest. death. Two decades ago, the median survival rate from diagnosis, despite the available supportive treatment, ${ }^{1}$ was less than 3 years. In the current era, 8 drugs from 3 pharmacologic classes (endothelin receptor antagonists, phosphodiesterase-5 inhibitors, and prostanoids), administered

Correspondence: Eftychia A Demerouti MD PhD MmedSc, Cardiology Department, Onassis Cardiac Surgery Center, Syngrou Avenue 356, Athens, 17674, Greece. E-mail: efidemer@otenet.gr.

DOI: $10.4187 /$ respcare. 02252 


\section{Complications Leading to Sudden Cardiac Death in Pulmonary Arterial Hypertension}

per os, via inhalation, subcutaneously, or intravenously, have been approved for PAH patients, improving survival. While the survival is better, pulmonary hypertension continues to cause substantial morbidity and mortality, as progression of the pulmonary vasculopathy leads to progressive RV failure. ${ }^{2}$ Moreover, new imaging modalities enable us to recognize major complications, previously missed.

Sudden cardiac death is now encountered more often in PAH patients. In the American National Institute of Health registry, 106 deaths were reported in a cohort of 194 patients with idiopathic PAH, of which $26 \%$ were sudden. ${ }^{3}$ Likewise, 99 out of 316 patients died in the Leuven database during follow-up, of whom 18 suddenly. ${ }^{3}$

We review the etiology, preventive measures, and management of complications associated with sudden cardiac death among PAH patients.

\section{Plausible Causes of Arrhythmia}

The mechanisms of sudden cardiac death associated with RV hypertension and arrhythmias are less well understood than are those associated with left ventricular (LV) disease. Arrhythmogenic substrate in rat hearts with monocrotaline-induced pulmonary hypertension may cause steeper RV electrical restitution and rate-dependent RV-LV action potential duration-dispersion, ${ }^{4}$ inducing ventricular tachycardia and fibrillation. A study of 201 pulmonary hypertension patients ${ }^{5}$ demonstrated that mean heart-rate corrected QT interval (QTc) and QTc dispersion (QTcd) were significantly increased in severely ill patients, compared to patients with mild to moderate pulmonary hypertension. In addition, in women these indices were positively correlated to mean pulmonary arterial pressure, identifying a possible substrate for ventricular arrhythmias.

Ventricular arrhythmias in PAH are predominantly described in patients with congenital heart disease. Congenital heart disease patients at increased risk for sudden cardiac death are those with tetralogy of Fallot, transposition of great arteries, congenitally corrected transposition of the great arteries, aortic stenosis, and univentricular heart disease. ${ }^{6,7}$ In these patients, arrhythmias represent an increasingly frequent cause of morbidity and mortality, ${ }^{8,9}$ but algorithms for risk stratification have not yet been established. ${ }^{9}$ Implantable cardioverter defibrillator is indicated for secondary prevention, provided that a reversible cause for the cardiac arrest has been excluded. Electrophysiologic study is indicated for spontaneous sustained ventricular tachycardia, which can be eliminated by catheter ablation or surgical resection. ${ }^{9}$ In patients with Eisenmenger physiology, supraventricular arrhythmias may predispose to sudden cardiac death, and it is therefore essential to restore and maintain sinus rhythm. ${ }^{10}$ In a series by Daliento et al, $42 \%$ of Eisenmenger patients were found to have supraventricular arrhythmias on routine electrocardiogram or 24-hour Holter monitoring during longterm follow-up. ${ }^{11}$

In contrast to patients with pulmonary hypertension due to left heart disease, malignant ventricular arrhythmias, such as ventricular tachycardia or ventricular fibrillation, are rarely present in PAH patients. ${ }^{12}$ In a series of 132 PAH patients with cardiac arrest, by Hoeper et al, ${ }^{13}$ ventricular fibrillation was found in only $8 \%$ of the cases. The hypothesis that pulmonary hypertension promotes spontaneous ventricular fibrillation in rats, during a critical post-pulmonary-hypertension onset period, was tested in a recently published study. ${ }^{14}$ The authors concluded that pulmonary-hypertension-induced RV fibrillation is associated with a distinct phase of increased mortality, characterized by spontaneous ventricular fibrillation arising from the $\mathrm{RV}$ by an early after-depolarization-mediated triggered activity.

In contrast, supraventricular tachyarrhythmias are quite frequent. In a study ${ }^{15}$ of $231 \mathrm{PAH}$ patients followed up for 6 years, supraventricular arrhythmias were reported with an annual incidence of $2.8 \%$, whereas the incidence of atrial flutter and of fibrillation were almost equal, leading to rapid clinical deterioration. Atrial flutter, originating from the right atrium, seems to occur more often in patients with severely impaired hemodynamics, but does not seem to be the substrate for sudden cardiac death. ${ }^{16}$

Atrial tachyarrhythmias are poorly tolerated in PAH because of decreased ventricular compliance, which renders RV filling dependent on the atrial contraction. ${ }^{17}$ Clinical improvement in $\mathrm{PAH}$ patients after atrial flutter isthmus ablation has been described. ${ }^{16}$

\section{Non-arrhythmic Causes}

The most relevant mechanisms for sudden cardiac death in PAH patients seem to be related to severe dilatation of the pulmonary artery, as subsequent complications, such as left main compression syndrome (LMCS), pulmonary artery dissection (PAD), pulmonary artery rupture (PAR), and massive hemoptysis, may take place.

\section{Left Main Compression Syndrome}

Pulmonary artery dilatation represents an important consequence of $\mathrm{PAH}$, and is commonly seen in echocardiographic studies as well as on computed tomography. Pulmonary artery dilatation is progressive and, surprisingly, is independent of the changes in pulmonary artery pressure, cardiac output, and even hemodynamics. ${ }^{18}$

LMCS due to extrinsic compression of the left main coronary artery by an enlarged pulmonary artery trunk is an uncommon cause of angina, LV dysfunction, and sudden cardiac death in patients with pulmonary hyperten- 


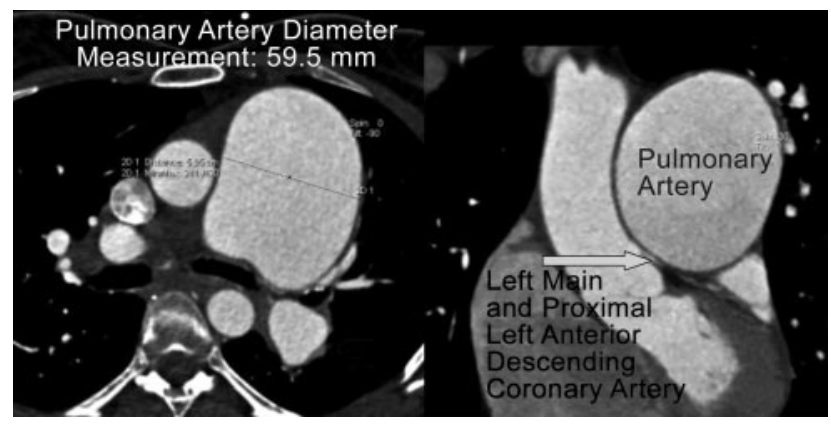

Fig. 1. Dual source computed tomogram used for pulmonary artery diameter measurement and left main compression syndrome detection.

$\operatorname{sion}^{19}$ (Fig. 1). According to various case studies, ${ }^{20-22}$ the true incidence of LMCS due to pulmonary artery dilatation is unknown but ranges from $5 \%$ to $44 \%$ of patients with pulmonary hypertension. A prominent risk factor for the development of LMCS seems to be the severity and duration of pulmonary hypertension.

Angina in PAH patients is a frequently reported symptom, predominantly caused by RV subendocardial ischemia due to RV dilatation and hypertrophy; however, cases of acute coronary syndrome ${ }^{23-25}$ or LV failure and cardiogenic shock ${ }^{24-26}$ have been reported. Ventricular tachyarrhythmias due to ischemia secondary to LMCS might contribute to an increased risk of sudden cardiac death in these patients. So, in case of angina in a patient with pulmonary hypertension, LMCS should be considered in the differential diagnosis.

The syndrome has been described in the setting of congenital heart defects such as atrial ${ }^{27}$ and ventricular septal defects and patent ductus arteriosus. ${ }^{28}$ Other underlying etiologies are idiopathic PAH, chronic thromboembolic pulmonary hypertension, and advanced parenchymal lung disease. ${ }^{28-30}$ Several structural changes are responsible for the extrinsic left main coronary artery compression, and pulmonary artery vascular remodeling seems to be crucial. In case of chronic pulmonary hypertension, intimal thickening, medial hypertrophy, fibrosis, and luminal dilatation appear in proximal pulmonary vessels. Pulmonary artery dilatation may lead to the displacement of the left main coronary artery. In a series ${ }^{28}$ by Kajita et al, pulmonary artery dilatation was present in all cases, with a mean main pulmonary artery-to-aortic root diameter ratio of 2.0. This was also confirmed by Mesquita et al, ${ }^{20}$ who reported, in a series of patients with pulmonary hypertension, a mean pulmonary artery diameter of $55 \mathrm{~mm}$ and a mean pulmonary artery-to-aortic root diameter ratio of 1.98 in patients with LMCS, compared with $37 \mathrm{~mm}$ and $1.46 \mathrm{in}$ those without.

Diagnosis of Left Main Compression Syndrome. In the presence of substantial dilatation of the main pulmonary artery, further evaluation should be performed to exclude LMCS, ${ }^{25}$ especially in patients with angina, as the likelihood of left main coronary artery compression in patients with PAH is positively related to both pulmonary artery diameter and the ratio of pulmonary artery diameter to aortic diameter. ${ }^{28}$ Cardiac computed tomography or magnetic resonance angiography are useful tools for noninvasive screening ${ }^{31}$; coronary angiography, ${ }^{25}$ however, is considered the gold standard for the final diagnosis of LMCS. ${ }^{32}$

Left main coronary artery compression is usually best visualized in the $45^{\circ}$ left anterior oblique view, with $30^{\circ}$ cranial angulation..$^{25,33}$ In this projection the left main coronary artery has an eccentric narrowing and appears to be inferiorly displaced, in close contact with the left aortic sinus, ${ }^{25}$ with a mean angle of $23^{\circ}$, compared with $70^{\circ}$ in the control group. Intravascular ultrasound study and fractional flow reserve estimation have also been used to evaluate the compression severity. ${ }^{23,32,34}$ Slight narrowing of the ostial left main coronary artery, without evidence of substantial atherosclerosis, is always present. Myocardial perfusion techniques do not seem to be of any help in establishing the diagnosis; according to the reported cases in the literature, only 4 out of 10 patients with documented LMCS had evidence of regional ischemia on nuclear myocardial imaging. ${ }^{28,33,35}$

Management of Left Main Compression Syndrome. In case of LMCS it is crucial to restore unobstructed coronary flow; this seems to reduce the incidence of sudden cardiac death. Treatment is indicated when angiographic compression is documented; noninvasive evaluation of myocardial ischemia does not seem to be of interest in this setting. ${ }^{32}$

The optimal therapeutic approach is, however, debatable. Surgical correction of the dilated pulmonary artery has been reported, ${ }^{25}$ and is associated with a reduction in left main coronary artery stenosis, from $85 \%$ to smaller than $50 \%$, as well as less inferior left main displacement. Coronary revascularization, however, is the surgical procedure of choice. ${ }^{36}$

Percutaneous coronary intervention combined with stent implantation seems to be a safe and effective option, avoiding the postoperative risk of RV failure in patients with increased pulmonary arterial pressure. ${ }^{31}$ Due to the absence of atherosclerotic disease, the risk of percutaneous intervention in these patients seems to be low. The lesion is most often ostial, and stenting is feasible, with a high procedural success rate and a low restenosis risk at followup. In 2001, Rich et $a^{37}$ reported successful left main coronary artery stenting in 2 patients with primary pulmonary hypertension and LMCS. Since then, several other authors ${ }^{23,38-41}$ have also reported successful angiographic and short-term clinical outcomes. Of note, all reported cases involved compression of the ostium or proximal left 
main coronary artery, sparing the left main bifurcation, so single stent placement was always sufficient.

\section{Pulmonary Artery Dissection and Rupture}

In patients without pulmonary hypertension, rare cases of idiopathic and inflammation-related PAD have been described. ${ }^{42,43}$ PAD and PAR have also been proposed as the underlying pathology in PAH patients presenting with cardiogenic shock and sudden death, ${ }^{44}$ more frequently diagnosed in Eisenmenger syndrome. ${ }^{45-49}$ PAD is related to medial degeneration, with fragmentation of elastic fibers, weakening of the wall, and dilatation of the pulmonary artery and its branches caused by chronic pulmonary hypertension. ${ }^{45,50,51}$ The increased intravascular pressure and subsequent shear stress may predispose to the development of an intimal tear. Whether medial degeneration causes the dissection, predisposes to intimal tears, or is simply the result of chronically elevated intravascular pressure remains controversial. ${ }^{47}$

Approximately 70 cases of PAD have been described, ${ }^{43-46,50-69}$ of which almost 10 were diagnosed during life. ${ }^{43,65-69}$ Congenital heart disease was the underlying condition in the majority of cases, with the patent ductus arteriosus representing the most common defect. Idiopathic $\mathrm{PAH}$ was present in 10 cases.

The main pulmonary artery trunk is the site of dissection in $80 \%$ of cases. In a small number of cases, PAD may occur at the site of localized aneurysms, which are most common in congenital heart disease. ${ }^{67}$ In contrast to aortic dissection, the false lumen in PAD tend to rupture rather than to develop a re-entry site. ${ }^{68}$ PAR may occur into the pericardium ${ }^{70-72}$ or pleural cavity, leading to sudden death, and usually involves the site of maximal diameter of the pulmonary artery.

The precipitating factor of death in 20 among 182 pulmonary hypertension patients was pulmonary artery dilatation, according to a recent study in Poland. Multivariate analysis identified pulmonary artery diameter $(P<.001)$ as independently contributing to the risk of sudden death. ${ }^{73}$

Iatrogenic (catheter-induced) rupture of the pulmonary artery is also a rare and life-threatening complication of right heart catheterization, and demands rapid therapy. Diffuse pulmonary bleeding or hemoptysis during right heart catheterization should immediately raise suspicion of iatrogenic PAD.

Diagnosis of Pulmonary Artery Dissection and Rupture. The diagnosis of PAD and PAR is usually made postmortem, as the majority of these patients experience sudden death. ${ }^{70}$ High suspicion is needed in a PAH patient presenting with acute dyspnea on exertion, retrosternal chest pain, central cyanosis, and sudden hemodynamic decompensation. ${ }^{69}$ Symptom initiation may occur during

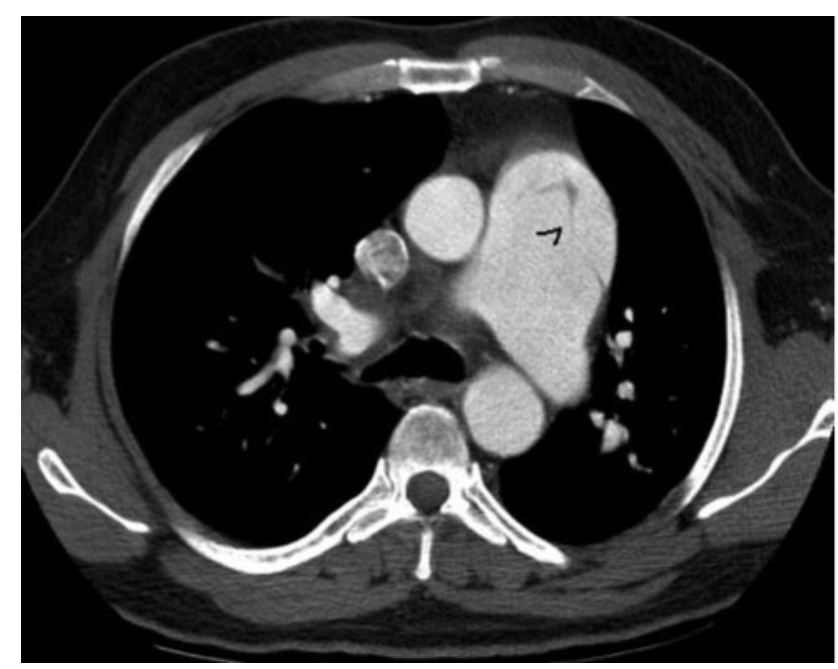

Fig. 2. Contrast-enhanced computed tomography pulmonary angiogram showing dilated central pulmonary arteries and an intimal flap in the main pulmonary artery (black arrowhead). (From Reference 74 , with permission.)

exercise, as an acute increase in pulmonary arterial pressure, combined with the inflammatory substrate in PAH.

The echocardiogram, because of its accessibility, remains a first line diagnostic tool, but contrast-enhanced computed tomography pulmonary angiography, or magnetic resonance angiography ${ }^{74}$ represents a powerful imaging modality in PAD and PAR (Fig. 2) for a timely surgical repair.

Management of Pulmonary Artery Dissection and Rupture. The low likelihood of this complication in PAH patients has not allowed for widely accepted management guidelines. The majority of all PAD cases described in the literature are iatrogenic, and various procedures have been performed. They include lung isolation in patients requiring intubation to protect the contralateral lung and to decrease bleeding in the affected lung, ${ }^{75}$ endovascular techniques such as metal-coil embolization, ${ }^{76}$ stent graft implantation leading to successful sealing of the pulmonary perforation, ${ }^{77}$ therapeutic embolism ${ }^{78}$ of the segmental artery by using a liquid, tissue-adhesive, occlusive agent (isobutyl-2-cyanoacrylate), embolization of the vessel by injection of thrombin, ${ }^{79}$ and embolization with gelatin foam. ${ }^{80}$

PAD is not often be encountered in PAH patients, ${ }^{48,81}$ but besides the above treatment options, urgent heartlung transplantation has been reported in experienced centers, ${ }^{47-49,82}$ and seems to be the necessary approach.

\section{Hemoptysis}

Massive hemoptysis is one of the most dreaded respiratory emergencies and is caused by various underlying 


\section{Complications Leading to Sudden Cardiac Death in Pulmonary Arterial Hypertension}

mechanisms. ${ }^{83}$ Severe hemoptysis leading to uncontrolled bleeding and sudden death appears to be uncommon, with a mortality rate exceeding $50 \%$ if appropriate treatment is not immediately provided. ${ }^{84-88}$

The source of massive hemoptysis ${ }^{89}$ is predominantly the bronchial circulation (90\%), rather than the pulmonary circulation $(5 \%)$, and in a minority of cases it may originate from the aorta or the systemic arterial supply to the lungs. ${ }^{90-92}$ In PAH the hypoxic vasoconstriction and the intravascular thrombosis ${ }^{93}$ reduce pulmonary circulation, resulting in bronchial artery proliferation and enlargement. ${ }^{89,94,95}$

The prominent collateral vessels and the hypertrophy of bronchial collateral arteries correlate with disease severity ${ }^{96}$ and sometimes induce extravasation into the respiratory tract, resulting in massive hemoptysis. ${ }^{97}$

According to the French national reference center experience, in contrast to PAH associated with congenital heart disease, idiopathic and heritable PAH hemoptysis represents a rare complication, with 20 cases reported over a 10 -year period. ${ }^{98}$ In chronic thromboembolic pulmonary hypertension, hemoptysis occurs more often and may be recurrent, as a result of dilated and hypertrophied bronchial collateral circulation. ${ }^{99}$ This complication can be life-threatening, with cumulative blood volumes averaging $79 \mathrm{~mL}(20-300 \mathrm{~mL})$. Survival rates of $60 \%, 43 \%$, and $36 \%$ at 1,3 , and 12 months, respectively, were documented, according to the French national reference center experience..$^{98}$

Since many PAH patients are treated with anticoagulants, therapeutic dilemma may ensue in case of concomitant hemoptysis.

Diagnosis of Hemoptysis. Diagnostic options for massive hemoptysis include radiography, bronchoscopy, and computed tomography, in an effort to elucidate the underlying cause as well as the exact location of the bleeding. ${ }^{100-102}$ Routine chest $\mathrm{x}$-ray is readily available and helpful; however, in a retrospective evaluation of 208 patients with hemoptysis, Hirshberg et al ${ }^{103}$ found that radiography was diagnostic in only $50 \%$ of cases. Bronchoscopy is by far more accurate, but the role of fiberoptic bronchoscopy in the setting of massive active hemoptysis is still controversial. The excessive blood in the bronchi, the risk of airway compromise by sedation, the delay in definitive treatment, the hypoxia, and the high cost are the main drawbacks of bronchoscopy. Computed tomography is extremely valuable in localization of bleeding, with higher accuracy than bronchoscopy, ${ }^{100,104}$ since it can detect both bronchial and non-bronchial vessels.

Management of Hemoptysis. Treatment of hemoptysis in PAH patients is not different from other causes of hemoptysis, for which there is no management consensus.
Neutralization of oral anticoagulants with vitamin K, and reversal of heparin with protamine, administration of the antifibrinolytic tranexamic acid, bronchoscopy, airway protection with balloon tamponade or double-lumen endotracheal tube, and selective embolization are the usual steps. ${ }^{3}$

Since the bronchial circulation is the major source of hemoptysis, in selected patients therapeutic embolization can be life-saving. ${ }^{105}$ In order to embolize the responsible vessel, a detailed angiography of the bronchial and pulmonary vascular tree is required. The concomitant embolization of non-bronchial systemic arteries at the same setting is favored if they are angiographically shown to contribute to the blood supply. Embolization of bronchial collaterals has been proposed in order to avoid recurrences of hemoptysis in patients with PAH. The selection of arteries to be embolized is based on the findings of computed tomography, bronchoscopy, and angiography, always in relation to the clinical situation. ${ }^{106}$ It has been proposed that repeated embolizations should not be considered as a definitive treatment in patients with PAH with recurrent bleeding. ${ }^{107}$

The complications of embolization have diminished gradually over the years, and include subintimal dissection of a bronchial artery, bronchial arterial perforation by a guide wire, and the reflux of embolic material into the aorta. ${ }^{105}$ Chest pain is the most common complication, possibly related to ischemia; dysphagia has also been reported. ${ }^{108,109}$ The most disastrous complication ${ }^{110,111}$ is spinal cord ischemia due to the inadvertent occlusion of spinal arteries, with a prevalence of $1.4-6.5 \%$.

\section{Syncope in PAH}

Syncope is characterized by transient loss of consciousness due to cerebral hypoperfusion, with rapid onset, short duration, and spontaneous complete recovery. It occurs from low cardiac output and represents a grim prognostic sign in PAH patients, requiring immediate treatment. ${ }^{112}$ The incidence of syncope in newly diagnosed adult patients in the current era is $12 \% .{ }^{113}$ Syncope increases the risk of death, and this is incremental to the risk attributable to other known prognostic factors.

Echocardiographic assessment provides useful information about pulmonary hemodynamics, but right heart catheterization is necessary to establish the diagnosis. Inotropic drugs and intravenous prostanoids are indicated to clinically stabilize the patient. Few studies have addressed the value of vasopressors and pulmonary vasodilators in critically ill PAH patients, as well as in patients successfully resuscitated after sudden cardiac death, but dobutamine, milrinone, inhaled nitric oxide, and intravenous prostacyclin are commonly utilized. ${ }^{114}$ 


\section{Complications Leading to Sudden Cardiac Death in Pulmonary Arterial Hypertension}

\section{Cardiac Arrest and Resuscitation in PAH Patients}

Cases of sudden cardiac death due to previously undiagnosed PAH have been described. The diagnosis in these cases is based on autopsy, and on the pathophysiological changes that apparently exist in PAH such as RV myocardial hypertrophy, dilated pulmonary conus, plexiform vascular lesions, and thrombotic lesions. In case of successful resuscitation, echocardiographic assessment and right heart catheterization are necessary for PAH diagnosis establishment.

Cardiopulmonary resuscitation in PAH patients has poor outcome, as shown in the retrospective survey by Hoeper et al. ${ }^{13}$ In a population of 3,130 PAH patients treated between 1997 and 2000 in 17 reference centers in Europe and the United States, 513 patients had a circulatory arrest. Resuscitation was unsuccessful in $79 \%$ of patients (104 patients), and only $6 \%$ (8 patients) survived for longer than 3 months.

According to a recent review, cardiopulmonary resuscitation is not indicated in patients with a combination of: New York Heart Association class IV symptoms; intractable right heart failure with more than 2 hospital admissions over the preceding 6 months; maximal PAH specific drug therapy (including parenteral prostaglandin I2); atrial septostomy if indicated; contraindication for lung transplantation; and persistent intolerable suffering from dyspnea, anxiety, and pain. ${ }^{3}$

\section{Summary}

$\mathrm{PAH}$ is a rare and severe disease characterized by pulmonary vascular remodeling, leading to right heart failure and premature death. LMCS must be taken into consideration in PAH patients with angina, as well as in those without symptoms but with high-risk anatomy, as in case of severe pulmonary artery dilatation. Computed tomography coronary angiography represents the initial method for LMCS exclusion. Coronary angiography should be performed when the findings of computed tomography coronary angiography are suspicious. Coronary revascularization is of vital importance in these patients; in the current era, percutaneous revascularization with stent implantation seems to be safe and effective.

Massive hemoptysis, mostly due to PAR, is usually lethal in PAH patients with severely dilated pulmonary artery, so PAH patients with recurrent hemoptysis might be placed on the lung transplant list.

PAD is rarely described in surviving patients; it represents a life-threatening condition that should be suspected in PAH patients presenting with chest pain or hemodynamic compromise. Nowadays, the high quality noninvasive imaging techniques allow us to diagnose this condition and subsequently treat it surgically.
PAH may present with various complications that may cause sudden cardiac death; appropriate diagnostic approach, rapid decision making, and successful management should be applied. The advent of disease-targeted therapy for severe PAH has reduced patient referral for lung transplantation programs; however, the identification of severe complications such as PAD or recurrent massive hemoptysis, once recognized, are indications for rapid registration on a waiting list.

Finally, it is now appreciated that specialized multidisciplinary teams in PAH referral centers provide emergency care, direct links, and quick referral for lung transplantation or thoracic surgery, thus contributing to improved quality of life and increased survival for PAH patients.

\section{REFERENCES}

1. Naeije R. Treatment of right heart failure on pulmonary arterial hypertension: is going left a step in the right direction. Eur Respir Rev 2010;19(115):4-6.

2. Hoeper MM, Granton J. Intensive care unit management of patients with severe pulmonary hypertension and right heart failure. Am J Respir Crit Care Med 2011;184(10):1114-1124.

3. Delcroix M, Naeije R. Optimising the management of pulmonary arterial hypertension patients: emergency treatments. Eur Respir Rev 2010;19(117):204-211.

4. Benoist D, Stones R, Drinkhill M, Bernus O, White E. Arrhythmogenic substrate in hearts of rats with monocrotaline-induced pulmonary hypertension and right ventricular hypertrophy. Am J Physiol Heart Circ Physiol 2011;300(6):H2230-H2237.

5. Hong-liang Z, Qin L, Zhi-hong L, Zhi-hui Z, Chang-ming X, Xinhai $\mathrm{N}$, et al. Heart rate-corrected QT interval and QT dispersion in patients with pulmonary hypertension. Wien Kin Wochenshr 2009; 121(9-10):330-333.

6. Oechslin EN, Harrison DA, Connelly MS, Webb GD, Siu SC. Mode of death in adults with congenital heart disease. Am J Cardiol 2000;86(10):1111-1116.

7. Zipes DP, Camm AJ, Borggerfe M, Buxton AE, Chaitman B, Fromer M et al. ACC/AHA/ESC 2006 guidelines for management of patients with ventricular arrhythmias and the prevention of sudden cardiac death-executive summary: a report of the American College of Cardiology/American Heart Association Task Force and the European Society of Cardiology Committee for Practice Guidelines Developed in collaboration with the European Heart Rhythm Association and the Heart Rhythm Society. Eur Heart J 2006;27(17): 2099-2140.

8. Somerville J. Management of adults with congenital heart disease: an increasing problem. Annu Rev Med 1997;48:283-293.

9. Baumgartner H, Bonhoeffer P, De Groot NM, de Haan F, Deanfield JE, Galie N, et al; Task Force on the Management of Grown-up Congenital Heart Disease of the European Society of Cardiology (ESC); Association for European Paediatric Cardiology (AEPC): ESC Committee for Practice Guidelines. ESC Guidelines for the management of grown-up congenital heart disease, new version 2010. Eur Heart J 2010;31(23):2915-2956.

10. Diller GP, Gatzoulis MA. Pulmonary vascular disease in adults with congenital heart disease. Circulation 2007;115(8):1039-1050.

11. Daliento L, Somerville J, Presbitero P, Menti L, Brach-Prever S, Rizzoli G, Stone S. Eisenmenger Syndrome. Factors related to deterioration and death. Eur Heart J 1998;19(12):1845-1855.

12. Galié N, Hoeper M, Humbert M, Torbicid A, Vachiery JL, Barbera JA, et al. Guidelines for the diagnosis and treatment of pulmonary 


\section{Complications Leading to Sudden Cardiac Death in Pulmonary Arterial Hypertension}

hypertension: the Task Force for the Diagnosis and Treatment of Pulmonary Hypertension of the European Society of Cardiology (ESC) and the European Respiratory Society (ERS), endorsed by the International Society of Heart and Lung Transplantation (ISHLT). Eur Heart J 2009;30(20):2493-2537. Erratum in: Eur Heart J 2011;32(8):926.

13. Hoeper MM, Galié N, Murali S, Olschewski H, Rubenfire M, Robbins IM, et al. Outcome after cardiopulmonary resuscitation in patients with pulmonary arterial hypertension. Am J Respir Crit Care Med 2002;165(3):341-344.

14. Umar S, Lee JH, De Lange E, Iorga A, Partow-Navid R, Bapat A, et al. Spontaneous ventricular fibrillation in right ventricular failure secondary to chronic pulmonary hypertension. Circ Arrhythm Electrophysiol 2011;5(1):181-190.

15. Tongers J, Schwerdtfeger B, Klein G, Kempf T, Schaefer A, Knapp $\mathrm{JM}$, et al. Incidence and clinical relevance of supraventricular tachyarrhythmias in pulmonary hypertension. Am Heart J 2007;153(1): 127-132.

16. Showkathali R, Tayebjee MH, Grapsa J, Alzetani M, Nihoyannopoulos P, Howard LS, et al. Right atrial flutter isthmus ablation is feasible and results in acute clinical improvement in patients with persistent atrial flutter and severe pulmonary arterial hypertension. Int J Cardiol 2011;149(2):279-280.

17. Goldstein JA, Harada A, Yagi Y, Barzilai B, Cox JL. Hemodynamic importance of systolic ventricular interaction, augmented right atrial contractility and atrioventricular synchrony in acute right ventricular dysfunction. J Am Coll Cardiol 1990;16(1):181-189.

18. Boerrigter B, Mauritz GJ, Marcus JT, Helderman F, Postmus PE, Westerhof N, Vonk-Noordegraaf A. Progressive dilatation of the main pulmonary artery is a characteristic of pulmonary arterial hypertension and is not related to changes in pressure. Chest 2010; 138(6):1395-1401.

19. Lee MS, Oyama J, Bhatia R, Kim YH, Park SJ. Left main coronary artery compression from pulmonary artery enlargement due to pulmonary hypertension: a contemporary review and argument for percutaneous revascularization. Catheter Cardiovasc Interv 2010; 76(4):543-550.

20. Mesquita SM, Castro CR, Ikari NM, Oliveira SA, Lopes AA. Likelihood of left main coronary artery compression based on pulmonary trunk diameter in patients with pulmonary hypertension. Am J Med 2004;116(6):369-374.

21. Mitsudo K, Fujino T, Matsunaga K, Doi O, Nishihara Y, Awa J, et al. [Coronary angiographic findings in the patients with atrial septal defect and pulmonary hypertension-compression of left main coronary artery by pulmoanry trunk]. Kokyu To Junkan 1989;37(6): 649-655. Article in Japanese.

22. Kothari SS, Chatterjee SS, Sharma S, Rajani M, Wasir HS. Left main coronary artery compression by dilated main pulmonary artery in atrial septal defect. Indian Heart J 1994;46(4):165-167.

23. Lindsey JB, Brilakis ES, Banerjee S. Acute coronary syndrome due to extrinsic compression of the left main coronary artery in a patient with severe pulmonary hypertension: successful treatment with percutaneous coronary intervention. Cardiovasc Revasc Med 2008; 9(1):47-51.

24. Vaseghi M, Lee J, Currier J. Acute myocardial infarction secondary to left main artery compression by pulmonary artery aneurysm in pulmonary arterial hypertension. J Invasive Cardiol 2007;19(12): 375-377.

25. Tespili M, Saino A, Personeni D, Silvestro A, Scopelliti P, Banfi C. Life-threatening left main stenosis induced by compression from a dilated pulmonary artery J Cardiovasc Med (Hagerstown) 2009; 10(2):183-187.

26. de Jesus Perez VA, Haddad F, Vagelos RH, Fearon W, Feinstein J, Zamanian RT. Angina associated with left main coronary artery compression in pulmonary hypertension. J Heart Lung Transplant 2009;28(5):527-530.

27. Jo Y, Kawamura A, Jinzaki M, Kohno T, Anzai T, Iwanaga S, et al. Extrinsic compression of the left main coronary artery by atrial septal defect. Ann Thorac Surg 2008;86(6):1987-1989.

28. Kajita LJ, Martinez EE, Ambrose JA, Lemos PA, Esteves A, Nogueira da Gama M, et al. Extrinsic compression of the left main coronary artery by a dilated pulmonary artery: clinical, angiographic, and hemodynamic determinants. Catheter Cardiovasc Interv 2001; 52(1):49-54.

29. Fujiwara K, Naito Y, Higashiue S, Takagaki Y, Goto Y, Okamoto $\mathrm{M}$, et al. Left main coronary trunk compression by dilated main pulmonary artery in atrial septal defect. Report of three cases. J Thorac Cardiovasc Surg 1992;104(2):449-452.

30. Ngaage DL, Lapeyre AC, McGregor CG. Left main coronary artery compression in chronic thromboembolic pulmonary hypertension. Eur J Cardiothorac Surg 2005;27(3):512.

31. Lee MS, Oyama J, Bhatia R, Kim YH, Park SJ. Left main coronary artery compression from pulmonary artery enlargement due to pulmonary hypertension: a contemporary review and argument for percutaneous revascularization. Catheter Cardiovasc Interv 2010; 76(4):543-50.

32. Piña Y, Exaire JE, Sandoval J. Dodd JD, Maree A, Palacios I, et al. Left main coronary artery extrinsic compression syndrome: a combined intravascular ultrasound and pressure wire. J Invasive Cardiol 2006;18:102-104.

33. Safi M, Eslami V, Shabestari AA, Saadat H, Namazi MH, Vakili H, Movahed MR. Extrinsic compression of left main coronary artery by the pulmoarny trunk secondary to pulmonary hypertension documented using 64-slice multidetector computed tomography coronary angiography. Clin Cardiol 2009;32(8):426-428.

34. Bonderman D, Fleischmann D, Prokop M, Klepetko W, Lang IM. Images in cardiovascular medicine. Left main coronary artery compression by the pulmoarny trunk in pulmonary hypertension. Circulation 2002;105(2):265.

35. Jodocy D, Friedrich GJ, Bonatti JO, Muller S, Laufer G, Pachinger $\mathrm{O}$, et al. Left main compression syndrome by idiopathic pulmonary artery aneurysm caused by medial necrosis Erdheim-Gsell combined with bicuspid pulmonary valve. J Thorac Cardiovasc Surg 2009;138(1):234-236.

36. Caldera AE, Cruz-Gonzalez I, Bezerra HG, Cury RC, Palacios IF, Cockrill BA, Inglessis-Azuaje I. Endovascular therapy for left main compression syndrome. Case report and literature review. Chest 2009;135(6): 1648-1650.

37. Rich S, McLaughlin VV, O'Neil W. Stenting to reverse left ventricular ischemia due to left main coronary artery compression in primary pulmonary hypertension. Chest 2001;120(4):1412-1415.

38. Gómez Varela S, Montes Orbe PM, Alcíbar Villa J, Egurbide MV, Sainz I, Barrenetxea Benguria JL. [Stenting in primary pulmonary hypertension with compression of the left main coronary artery]. Rev Esp Cardiol 2004;57(7):695-698. Article in Spanish.

39. Dubois CL, Dymarkowski S, Cleemput JV. Compression of the left main pulmaorny artery in a patient with the Eisenmenger syndrome. Eur Heart J 2007;28(16):1945.

40. Vaseghi M, Lee JS, Currier JW. Acute myocardial infarction secondary to left main coronary artery compression by pulmonary artery aneurysm in pulmonary arterial hypertension. J Invasive Cardiol 2007;19(12):375-377.

41. Dodd JD, Maree A, Palacios I, de Moor MM, Mooyaart EA, Shapiro MD, et al. Images in cardiovascular medicine: left main coronary artery compression syndrome; evaluation with 64-slice cardiac multidetector computed tomography. Circulation 2007;115(1): e7-e8. 


\section{Complications Leading to Sudden Cardiac Death in Pulmonary Arterial Hypertension}

42. Wunderbaldinger P, Bernhard C, Uffmann M, Kurkciyan I, Senbaklavaci $\mathrm{O}$, Herold $\mathrm{CJ}$. Acute pulmonary trunk dissection in a patient with primary pulmonary hypertension. J Comput Assist Tomogr 2000;24(1):92-95.

43. Inayama Y, Nakatani Y, Kitamura H. Pulmonary artery dissection in patients without underlying pulmonary hypertension. Histopathology 2001;38(5):435-442. Erratum in: Histopathology 2001; 39(5):550.

44. Walley VM, Virmani R, Silver MD. Pulmonary arterial dissections and ruptures: to be considered in patients with pulmonary arterial hypertension presenting with cardiogenic shock or sudden death. Pathology 1990;22(1):1-4.

45. Yamamoto ME, Jones JW, McManus BM. Fatal dissection of the pulmonary trunk. An obscure consequence of chronic pulmonary hypertension. Am J Cardiovasc Pathol 1988;1(3):353-359.

46. Masuda S, Ishii T, Asuwa N, Ishikawa Y, Kiguchi H, Uchiyama T. Concurrent pulmonary arterial dissection and saccular aneurysm associated with primary pulmonary hypertension. Arch Pathol Lab Med 1996;120(3):309-312.

47. Khattar RS, Fox DJ, Alty JE, Arora A. Pulmonary artery dissection: an emerging cardiovascular complication in surviving patients with chronic pulmonary hypertension. Heart 2005;91(2):142-145.

48. Tonder N, Kober L, Hassager C. Pulmonary artery dissection in a patient with Eisenmenger syndrome treated with heart and lung transplantation. Eur J Echocardiogr 2004;5(3):228-230.

49. Ejima K, Uchida T, Hen Y, Nishio Y, Nomoto F, Uchida Y, et al. Silent pulmonary artery dissection in a patient with Eisenmenger syndrome due to ventricular septal defect: a case report. J Cardiol 2005;46(1):33-37.

50. Shilkin KB, Low LP, Chen BT. Dissecting aneurysm of the pulmonary artery. J Pathol 1969;98(1):25-29.

51. Lüchtrath H. Dissecting aneurysm of the pulmonary artery. Virchows Arch A Pathol Anat Histol 1981;391(2):241-247.

52. Best J. Dissecting aneurysm of the pulmonary artery with multiple cardiovascular abnormalities and pulmonary hypertension. Med J Aust 1967;2(25):1129-1130.

53. Palcik B, Rodbard S, McMahon J, Swaroop S. Pulmonary artery dissection and rupture in Eisenmenger's syndrome. Vasc Surg 1976; 10(2):72-80.

54. Gómez-Arnau J, Montero CG, Luengo C, Gilsanz FJ, Avello F. Retrograde dissection and rupture of pulmonary artery after catheter use in pulmonary hypertension. Crit Care Med 1982;10(10):694695.

55. Rosenblum SE, Ratliff NB, Shirey EK, Sedmak DD, Taylor PC. Pulmonary artery dissection induced by a Swan-Ganz catheter. Cleve Clin Q 1984;51(4):671-675.

56. Hankins GD, Brekken AL, Davis LM. Maternal death secondary to a dissecting aneurysm of the pulmonary artery. Obstet Gynecol 1985;65(3 Suppl):45S-48S.

57. Nagelsmit MJ, Eulderink F. Dissecting aneurysm of the pulmonary artery trunk. Am J Cardiol 1986;58(7):660-661.

58. Steingrub J, Detore A, Teres D. Spontaneous rupture of pulmonary artery. Crit Care Med 1987;15(3):270-271.

59. Nguyen GK, Dowling GP. Dissecting aneurysm of the pulmonary artery trunk. Arch Pathol Lab Med 1989;113(10):1178-1179.

60. Sardesai SH, Marshall RJ, Farrow R, Mourant AJ. Dissecting aneurysm of the pulmonary artery in a case of unoperated patent ductus arteriosus. Eur Heart J 1990;11(7):670-673.

61. Andrews R, Colloby P, Hubner PJ. Pulmonary artery dissection in a patient with idiopathic dilatation of the pulmonary artery: a rare cause of sudden death. Br Heart J 1993;69(3):268-269.

62. Green NJ, Rollason TP. Pulmonary artery rupture in pregnancy complicating patent ductus arteriosus. Br Heart J 1992;68(6):616618.
63. Thierrien J, Gerlis LM, Kilner P, Somerville J. Complex pulmonary atresia in an adult: natural history, unusual pathology and mode of death. Cardiol Young 1999;9(3):249-256.

64. Rosenson RS, Sutton MS. Dissecting aneurysm of the pulmonary artery trunk in mitral stenosis. Am J Cardiol 1986;58(11):11401141.

65. Steurer J, Jenni R, Medici TC, Vollrath T, Hess OM, Siegenthaler W. Dissecting aneurysm of the pulmonary artery with pulmonary hypertension. Am Rev Respir Dis 1990;142(5):1219-1221.

66. Stern EJ, Graham C, Gamsu G, Golden JA, Higgins CB. Pulmonary artery dissection: MR findings. J Comput Assist Tomogr 1992; 16(3):481-483.

67. Lopez-Candales A, Kleiger RE, Aleman-Gomez J, Kouchoukos NT, Botney MD. Pulmonary artery aneurysm: review and case report. Clin Cardiol 1995;18(12):738-740.

68. Senbaklavaci O, Kaneko Y, Bartunek A, Brunner C, Kurkciyan E, Wunderbaldinger $\mathrm{P}$, et al. Rupture and dissection in pulmonary artery aneurysms: incidence, cause, and treatment-review and case report. J Thorac Cardiovasc Surg 2001;121(5):1006-1008.

69. Song EK, Kolecki P. A case of pulmonary artery dissection diagnosed in the emergency department. J Emerg Med 2002;23(2): 155-159.

70. Arena V, De Giorgio F, Abbate A, Capelli A, De Mercurio D, Carbone A. Fatal pulmonary arterial dissection and sudden death as initial manifestation of primary pulmonary hypertension: a case report. Cardiovasc Pathol 2004;13(4):230-232.

71. Le Bret E, Lupoglazoff JM, Bachet J, Carbognani D, Bouabdallah K, Folliguet T, Laborde F. Pulmonary artery dissection and rupture associated with aortopulmonary window. Ann Thorac Surg 2004; 78(4):e67-e68.

72. Hsu HH, Tzao C, Tsai CS, Sun GH, Chen CY. Acute concomitant pulmonary artery and aortic dissection with rupture Int J Cardiovasc Imaging 2007;23(3):411-414.

73. Żyłkowska J, Kurzyna M, Florczyk M, Burakowska B, Gregorczyk F, Burakowski J, et al. Pulmonary artery dilatation correlates with the risk of unexpected death in chronic arterial or thromboembolic pulmonary hypertension. Chest 2012;142(6):1406-1416.

74. Neimatallah MA, Whassan MD, Moursi M, Kadhi YAL. CT findings of pulmonary artery dissection. Br J Radiol 2007;80(951): e61-e63.

75. Klafta JM, Olson JP. Emergent lung separation for management of pulmonary artery rupture. Anesthesiology 1997;87(5):1248-1250.

76. Gottwalles Y, Wunschel-Joseph ME, Hanssen M. Coil embolization treatment in pulmonary artery branch rupture during SwanGanz catheterization. Cardiovasc Intervent Radiol 2000;23(6):477479.

77. Zuffi A, Biondi-Zoccai G, Colombo F. Swan-Ganz-induced pulmonary artery rupture: management with stent graft implantation. Catheter Cardiovasc Interv 2010;76(4):578-581.

78. Jondeau G, Lacombe P, Rocha P, Rigaud M, Hardy A, Bourdarias JP. Swan-Ganz catheter-induced rupture of the pulmonary artery: successful early management by transcatheter embolization. Cathet Cardiovasc Diagn 1990;19(3):202-204.

79. Damm C, Degen H, Stoepel C, Haude M. [Management of a catheter-induced rupture of a pulmonary artery]. Dtsch Med Wochenschr 2010;135(39):1914-1917. Article in German.

80. Kaiser CA, Hügli RW, Haegeli LM, Pfisterer ME. Selective embolization of a pulmonary artery rupture caused by a Cournand catheter. Catheter Cardiovasc Interv 2004;61(3):317-319.

81. Degan B. Emergency treatments in pulmonary arterial hypertension: a place for algorithms and for education programmes. Eur Respir Rev 2010;19:171-172.

82. Wuyts WA, Herijgers P, Budts W, De Wever W, Delcroix M. Extensive dissection of the pulmonary artery treated with combined 


\section{Complications Leading to Sudden Cardiac Death in Pulmonary Arterial Hypertension}

heart-lung transplantation. J Thorac Cardiovasc Surg 2006;132(1): 205-206.

83. Jean-Baptiste E. Clinical assessment and management of massive hemoptysis. Crit Care Med 2000;28(5):1642-1647.

84. Crocco JA, Rooney JJ, Fankushen DS, DiBenedetto RJ, Lyons HA. Massive hemoptysis. Arch Intern Med 1968;121(6):495-498.

85. Garzon AA, Cerruti M, Gourin A, Karlson KE. Pulmonary resection for massive hemoptysis. Surgery 1970;67(4):633-638.

86. Garzon AA, Gourin A. Surgical management of massive hemoptysis: a ten-year experience. Ann Surg 1978;187(3):267-271.

87. Najarian KE, Morris CS. Arterial embolization in the chest. J Thorac Imaging 1998;13(2):93-104.

88. Marshall TJ, Jackson JE. Vascular intervention in the thorax: bronchial artery embolization for hemoptysis. Eur Radiol 1997;7(8): 1221-1227.

89. Remy-Jardin M, Duhamel A, Deken V, Bouaziz N, Dumont P, Remy J. Systemic collateral supply in patients with chronic thromboembolic and primary pulmonary hypertension: assessment with multi-detector row helical CT angiography. Radiology 2005;235(1): 274-281.

90. MacIntosh EL, Parrott JC, Unrhu HW. Fistulas between the aorta and tracheobronchial tree. Ann Thorac Surg 1991;51(3):515-519.

91. Håkanson E, Konstantinov IE, Fransson SG. Management of lifethreatening haemoptysis. Br J Anaesth 2001;88(2):291-295.

92. Dearse EO, Bryan AJ. Massive hemoptysis 27 years after surgery for coarctation of the aorta. J R Soc Med 2001;94(12):640-664.

93. Deffenbach ME, Charan NB, Lakshminarayan S, Butler J. The bronchial circulation: small, but a vital attribute to the lung. Am Rev Respir Dis 1987;135(2):463-481.

94. Endrys J, Hayat N, Cherian G. Comparison of bronchopulmonary collaterals and collateral blood flow in patients with chronic thromboembolic and primary pulmonary hypertension. Heart 1997;78(2): 171-176.

95. Ley S, Kreitner KF, Morgenstern I, Thelen M, Kauczor HU. Bronchopulmonary shunts in patients with chronic thromboembolic pulmonary hypertension: evaluation with helical CT and MR imaging. AJR Am J Roentgenol 2002;179(5):1209-1215.

96. Grubstein A, Benjaminov O, Dayan D, Shitrit D, Cohen M, Kramer M. Computed tomography angiography in pulmonary hypertension. Isr Med Assoc J 2008;10(2):117-120.

97. Liebow AA, Hales MR, Lindskog GE. Enlargement of the bronchial arteries, and their anastomosis with the pulmonary arteries in bronchiectasis. Am J Pathol 1949;25(2):211-231.

98. Jais X. Hemoptysis in pulmonary arterial hypertension (PAH): a life-threatening complication (abstract). Am J Respir Crit Care Med 2009;179:A2667.

99. Remy J, Remy-Jardin M, Voisin C. Endovascular management of bronchial bleeding. In: Butler J, editor. The bronchial circulation. Lung Biology in Health and Disease series, volume 57. New York: Marcel Dekker; 1992:667-723.
100. Hsiao EI, Kirsch CM, Kagawa FT, Wehner JH, Jensen WA, Baxter RB. Utility of fiberoptic bronchoscopy before bronchial artery embolization for massive hemoptysis. AJR Am J Roentgenol 2001; 177(4):861-867.

101. Naidich DP, Funt S, Ettenger NA, Arranda C. Hemoptysis: CTbronchoscopic correlations in 58 cases. Radiology 1990;177(2): 357-362.

102. McGuinness G, Beacher JR, Harkin TJ, Garay SM, Rom WN, Naidich DP. Hemoptysis: prospective high-resolution CT/bronchoscopic correlation. Chest 1994;105(4):1155-1162.

103. Hirshberg B, Biran I, Glazer M, Kramer MR. Hemoptysis: etiology, evaluation, and outcome in a tertiary referral hospital. Chest 1997;112(2):440-444.

104. Abal AT, Nair PC, Cherian J. Haemoptysis: aetiology, evaluation, and outcome. A prospective study in a third-world country. Respir Med 2001;95(7):548-552.

105. Swanson K, Johnson C, Prakash U, McKusick M, Andrews J, Stanson A. Bronchial artery embolization: experience with 54 patients. Chest 2002;121(3):789-795.

106. Yoon W, Kim JK, Kim YH, Chung TW, Kang HK. Bronchial and nonbronchial systemic artery embolization for life-threatening hemoptysis: a comprehensive review. Radiographics 2002;22(6): 1395-1409.

107. Zyłkowska J, Kurzyna M, Pietura R, Fijałkowska A, Florczyk M, Czajka C, Torbicki A. Recurrent hemoptysis: an emerging lifethreatening complication in idiopathic pulmonary arterial hypertension. Chest 2011;139(3):690-693.

108. Ramakantan R, Bandekar VG, Gandhi MS, Aulakh BG, Deshmukh HL. Massive hemoptysis due to pulmonary tuberculosis: control with bronchial artery embolization. Radiology 1996;200(3): 691-694.

109. Tonkin IL, Hanissian AS, Boulden TF, Baum SL, Gavant ML, Gold RE, et al. Bronchial arteriography and embolotherapy for hemoptysis in patients with cystic fibrosis. Cardiovasc Intervent Radiol 1991;14(4):241-246.

110. Tanaka N, Yamakado K, Murashima S, Takeda K, Matsumura K, Nakagawa $\mathrm{T}$, et al. Superselective bronchial artery embolization for hemoptysis with a coaxial microcatheter system. J Vasc Intervent Radiol 1997;8(1 Pt 1):65-70.

111. Wong ML, Szkup P, Hopley MJ. Percutaneous embolotherapy for life-threatening hemoptysis. Chest 2002;121(1):95-102.

112. Rubin LJ, Badesch DB. Evaluation and management of the patient with pulmonary arterial hypertension. Ann Intern Med 2005;143(4): 282-292.

113. Le RJ, Fenstad ER, Maradit-Kremers H, McCully RB, Frantz RP, McGoon MD, Kane GC. Syncope in adults with pulmonary arterial hypertension. J Am Coll Cardiol 2011;58(8):863-867.

114. Zamanian RT, Haddad F, Doyle RL, Weinacker AB. Management strategies for patients with pulmonary hypertension in the intensive care unit. Crit Care Med 2007;35(9):2037-2050. 